\title{
Erratum to: Chronicle of the 1865, NE flank eruption of Mt. Etna and geomorphologic survey of the Mts. Sartorius area
}

Pietro Carveni - Giuliana Mele • Santo Benfatto • Sebastiano Imposa • Maria Salleo Puntillo

Published online: 2 September 2011

(C) Springer-Verlag 2011

\section{Erratum to: Bull Volcanol}

\section{DOI 10.1007/s00445-011-0497-5}

In the introduction, the evolution of Etna's activity is erroneously described in terms of Ma instead of ka. The sentences should read: "Its activity began at $\sim 500 \mathrm{ka}$ with fissure-fed, undersea eruptions of tholeiitic lava, and became sub-aerial at $\sim 320 \mathrm{ka}$ following regional uplift. From $\sim 110 \mathrm{ka}$, eruptions started to occur mostly through a central conduit exhibiting both explosive and effusive activity (e.g., Rittmann 1973; Romano et al. 1979; Romano 1982; Chester et al. 1985; Gillot et al. 1994; Branca et al. 2008).”

The online version of the original article can be found at http://dx.doi. org/10.1007/s00445-011-0497-5.

P. Carveni

Via Mario Vaccaro, 19,

95125 Catania, Italy

G. Mele $(\bowtie)$

Istituto Nazionale di Geofisica e Vulcanologia,

Via di Vigna Murata, 605,

00143 Rome, Italy

e-mail: giuliana.mele@ingv.it

S. Benfatto $\cdot$ M. S. Puntillo

Via San Marco, 91,

95047 Paternò, CT, Italy

S. Imposa

Dipartimento di Scienze Geologiche, Università di Catania,

Corso Italia, 57,

95129 Catania, Italy 